\title{
Florid Follicular Hyperplasia
}

National Cancer Institute

\section{Source}

National Cancer Institute. Florid Follicular Hyperplasia. NCI Thesaurus. Code C139029.

A morphologic finding indicating the presence of prominent follicular hyperplasia in a lymph node sample. 